\title{
Dexmedetomidine Versus Propofol Sedation in Flexible Bronchoscopy: A Randomized Controlled Trial and a Systematic Review and Meta-Analysis
}

Barak Pertzov ( $\sim$ pertzovb@gmail.com )

Rabin Medical Center

Boris Krasulya

Rabin Medical Center

Karam Azem

Rabin Medical Center

Yael Shostak

Rabin Medical Center

Shimon Izhakian

Rabin Medical Center

Dror Rosengarten

Rabin Medical Center

Svetlana Khaershenko

Rabin Medical Center

Mordechai Reuven Kramer

Rabin Medical Center

\section{Research Article}

Keywords: Dexmedetomidine, Flexible bronchoscopy, Sedation, Desaturation, Adverse events

Posted Date: January 7th, 2022

DOI: https://doi.org/10.21203/rs.3.rs-1218948/v1

License: (c) (1) This work is licensed under a Creative Commons Attribution 4.0 International License.

Read Full License 


\section{Abstract}

\section{Background:}

Dexmedetomidine (DEX), is a highly selective alpha2 adrenoceptor (a2-AR) agonist, successfully used in various procedures including flexible bronchoscopy. Randomized controlled trials (RCTs) evaluating DEX sedation during bronchoscopy report equivocal results regarding respiratory and hemodynamic outcomes.

\section{Methods}

We conducted an RCT to evaluate the efficacy of dexmedetomidine compared to propofol for sedation during bronchoscopy. The primary outcome was desaturation events, secondary outcomes were transcutaneous Pco2 level, hemodynamic adverse events and physician and patient satisfaction. We have also conducted A systematic review and meta-analysis of all RCTs evaluating DEX sedation during flexible bronchoscopy, included current study results.

\section{Results}

Overall, 63 patients were included, 30 and 33 in the DEX and propofol groups, respectively. The number of desaturation events was similar between groups, median (IQR) $1(0-1)$ and $1(0-2)$ in the DEX and control groups, respectively $(P=0.29)$. Median desaturation time was $1(0-2)$ and $1(0-3)$ minutes in the DEX and control groups, respectively $(P=0.48)$. Adverse events included hypotension, $33 \%$ vs $21.1 \%$ in intervention and control groups, respectively $(P=0.04)$, bradycardia, cough, and delayed recovery from sedation. Total adverse events were 22 and 7 in DEX and propofol groups, respectively $(P=0.009)$. The pooled metaanalysis included 13 trials (1604 participants) showed a significantly lower rate of desaturation events in the DEX group (RR $0.67,95 \% \mathrm{Cl} 0.57$ to 0.79 ) with a significantly higher rate of hypotension and bradycardia events (RR $1.55,95 \% \mathrm{Cl} 1.16$ to 2.06 and $\mathrm{RR} 1.91,95 \% \mathrm{Cl} 1.04$ to 3.5 , respectively)

\section{Conclusion}

Dexmedetomidine sedation resulted in a significantly reduced rate of desaturation events in comparison to propofol, midazolam and fentanyl. However, it was also associated with a higher rate of hypotension and bradycardia.

Trial registration : NCT04211298, registration date: 26/12/2019

\section{Background}

Fiberoptic bronchoscopy (FOB) is commonly used for the diagnosis and management of a variety of lung diseases $[1,2]$. The procedure is usually performed under sedation, with a selection of available methods to provide different depths and lengths of sedation, according to the type of procedure and operator preference $[3,4]$. Dexmedetomidine (DEX) is a highly selective alpha2 adrenoceptor (a2-AR) agonist, it 
has sedative, anxiolytic and analgesic qualities. Following intravenous administration, DEX has a distribution half-life of six minutes and a terminal elimination half-life $\left(\mathrm{t}^{1} / 2\right)$ of approximately two hours. Reported adverse events include both hypotension and hypertension, bradycardia, dry mouth and nausea $[5,6]$. DEX has been successfully used in a wide array of procedures including colonoscopy, endoscopic retrograde cholangio-pancreatography (ERCP), laparoscopic procedures, shockwave lithotripsy, awake carotid endarterectomy, retinal surgery and in pediatric patients [7-15]. In 2012 Ryu et al. conducted the first randomized controlled trial (RCT) that evaluated the use of DEX during bronchoscopy. The DEX group had a significantly lower rate of desaturation events with no between group difference in level of sedation, oxygen saturation, mean arterial pressure and heart rate[16]. During the period from 2012 to 2021 eleven more RCTs were conducted to evaluate DEX during bronchoscopy in comparison to propofol, midazolam and fentanyl in various combinations. While some of these trials reported a lower rate of desaturation events and an adequate sedation level, others reported no difference in desaturation events, a higher rate of hemodynamic adverse events and an inferior level of patient sedation and bronchoscopist satisfaction[17-27]. Therefore, DEX sedation for bronchoscopy is considered an emerging method for sedation during bronchoscopy. However, whether DEX sedation conveys a lower rate of desaturation events or adequate sedation level is yet to be determined. In this study we conducted an RCT to evaluate sedation with DEX in comparison to propofol during bronchoscopy and included the results in a systematic review and meta-analysis of all RCTs conducted to date.

\section{Methods}

We conducted a single center, RCT, that compared the use of dexmedetomidine to propofol, as the main drug for sedation during bronchoscopy. Patients were recruited between December 2019 to April 2020 and from January to May 2021. During these time intervals adult patients (age > 18 years) who were scheduled to undergo Bronchoscopy at Rabin Medical Center (RMC) in Israel, were offered to participate in the study. Exclusion criteria included: known or suspected allergy to any of the study drugs, seizure disorder, renal impairment (with serum creatinine $>2 \mathrm{mg} / \mathrm{dL}$ ) or hepatic impairment (elevated liver enzymes $>2$ times normal levels), hemodynamic instability (bradycardia with $\mathrm{HR}<50 \mathrm{bpm}$ or hypotension with SBP $<90 \mathrm{mmHg}$ ), or seriously ill patients with American Society of Anesthesiologists' (ASA) physical status above III. The study was approved by RMC institutional review board (IRB) (RMC0312-19) and registered in a clinical trial registry (NCT04211298, registration date: 26/12/2019). After signing an informed consent form the patient was randomized with computer generated random numbers sealed in opaque envelopes to either DEX group or propofol group.

\section{Sedation protocol}

An anesthesiologist was present throughout each procedure and oversaw monitoring and sedation protocol in all cases. Monitoring included continuous electrocardiography, pulse oximetry, transcutaneous PCO2 and automated noninvasive blood pressure recordings. All patients received supplemental nasal oxygen at $2-5 \mathrm{l} / \mathrm{min}$. The sedation protocols for both groups included a loading dose of fentanyl 1 $\mathrm{mcg} / \mathrm{kg}$ and midazolam $1 \mathrm{mg}$. Patients randomized to the DEX group received a loading dose of 1 
$\mathrm{mcg} / \mathrm{kg}$ over 15 minutes followed by a continuous intravenous infusion at a rate of $0.5 \mathrm{mcg} / \mathrm{kg} / \mathrm{h}$. Patients in the propofol group received a dose of $0.5-1 \mathrm{mg} / \mathrm{kg}$ for induction over $1 \mathrm{~min}$ followed by a maintenance infusion in a dose of $100-200 \mathrm{mcg} / \mathrm{kg} / \mathrm{min}$. In both groups bolus doses of propofol of 0.1 $0.5 \mathrm{mg} / \mathrm{kg}$ were given for insufficient sedation.

\section{Outcomes}

The primary outcomes were the number of de-saturation events, during bronchoscopy and the time in which the oxygen saturation level decreased under $90 \%$. Secondary outcomes were the level of transcutaneous PCO2 (PcCO2), blood pressure, number of propofol boluses given for insufficient sedation, length of procedure and adverse events. Bronchoscopist satisfaction level and patient discomfort were also evaluated on a scale of 1 to 5 . For physician satisfaction 5 represents high satisfaction and 1 poor satisfaction. For patient discomfort 5 represents no discomfort and 1 maximal discomfort.

\section{Statistical analysis}

The baseline characteristics and secondary outcomes were analyzed with the student's t-test, chi-square test and the Mann-Whitney U test, as appropriate. The primary outcome was analyzed with the chisquare test for the number of desaturation events and with the Mann-Whitney $U$ test for the time in which desaturation was recorded. A P-value of 0.05 was considered as significant. Statistical analysis was conducted with the SPSS version 27 software.

\section{Systematic review and meta-analysis}

We performed a systematic review and meta-analysis of all RCTs published through June 2021, assessing the benefit of dexmedetomidine for sedation during bronchoscopy. The primary outcome was the number of patients with any desaturation event. Secondary outcomes were hemodynamic adverse events: hypotension, hypertension, bradycardia, and tachycardia. The review was conducted according to the methodological recommendations of the Cochrane Handbook for Systematic Reviews of Interventions and the Preferred Reporting Items for Systematic Reviews and Meta-Analyses (PRISMA) statement $[28,29]$.

\section{Search strategy}

We searched MEDLINE (Ovid SP, 1966 to June 2021) and Cochrane Central Register of Controlled Trials (CENTRAL; 2021, Issue 6) databases for relevant trials. The search strategy for both databases is detailed in the supplementary material (supplementary appendix 1 ). We did not apply restrictions to language or publication status. Furthermore, we reviewed the ClinicalTrials.gov registry for ongoing and unpublished trials as well as the reference lists and citations of included trials and any relevant systematic reviews to identify additional trials. 
Two authors (BP and BK) independently applied the inclusion criteria to all identified and retrieved articles. In addition, the two authors independently performed data extraction using a data extraction form. Whenever data was missing, we attempted to contact the authors of the study to request the missing information.

\section{Assessment of risk of bias}

Two authors (BP and SK) independently assessed the risk of bias in included studies. We used a domainbased evaluation as recommended by the Cochrane Handbook for Systematic Reviews of Interventions [30]. We were not blinded to trial authors, publication status or other study characteristics. The following domains were assessed for this review: random sequence generation, allocation concealment, blinding of participants, personnel and outcome assessors, incomplete outcome data, selective reporting, and early stop of the trial.

\section{Statistical reporting}

We performed all statistical calculations using RevMan 5 (version 5.3). We calculated a weighted treatment effect across trials. We expressed results as risk ratio (RR) with $95 \%$ confidence interval (Cl) for dichotomous outcomes, and as mean differences (MD, 95\% Cl) for continuous outcomes. Results were included in intention to treat (ITT) analysis for all outcomes. We assessed heterogeneity in the results of the trials using the $\mathrm{I}^{2}$ statistic to measure inconsistency [28]. We visually examined funnel plots to assess small-study effects and risk of publication bias. If no significant heterogeneity was found, meta-analysis was done using the Mantel- Haenszel fixed-effects model. If significant heterogeneity was found $\left(\mathrm{I}^{2}>\right.$ $40 \%$, the meta-analysis was done using the Mantel-Haenszel random-effects model [30].

\section{Quality of evidence}

The Grading of Recommendations, Assessment, Development and Evaluation (GRADE) system was used to rate the quality of evidence for each outcome with the following factors: the limitations in study design or execution, inconsistency of results, indirectness of evidence, imprecision and publication bias [31, 32].

\section{Results}

Overall, 63 patients were included in the current study, 30 patients in the DEX group and 33 in the propofol group. Mean age in the intervention and control groups was $58.76 \pm 15.09$ and $62.96 \pm 9.69$, respectively $(P=0.19)$. Weight, ASA score and baseline $\mathrm{CO} 2$ were similar between groups. Male sex was more common in the propofol group, $69 \%$ vs $43 \%$ in the control and intervention groups, respectively $(P=0.03)$. Procedure types were balanced between groups (Table 1 ). The number of desaturation events was similar between groups, median (IQR) $1(0-1)$ and $1(0-2)$ in the intervention and control groups, respectively $(P=0.29)$. The median desaturation time was $1(0-2)$ and $1(0-3)$ minutes in the intervention and control groups respectively $(\mathrm{P}=0.48)$. The median rise in $\mathrm{PcCO} 2$ was 18.45 (14.70-22.97) and 20.65 (15.37-30.07) $\mathrm{mm} / \mathrm{Hg}$ and the median time in which PcCO2 was above $50 \mathrm{~mm} / \mathrm{Hg}$ was 17.5 (14.12-27.12) and 19.5 
(7.75-29.75) minutes in the intervention and control groups, respectively $(P=0.46$ and $P=0.94)$. Patients in the DEX group required a median of $2.5(2-5)$ propofol rescue boluses during the procedure in comparison to $2(1.0-2.5)$ boluses in the propofol group $(P=0.01)$, the median of total propofol dose of additional rescue boluses was $90 \mathrm{mg}$ (50-109) and $58 \mathrm{mg}$ (42-106.5) in the intervention and control groups, respectively $(P=0.18)$. Median procedure time was 20 (8-35) and 21 (15-27.5) minutes in the intervention and control groups, respectively $(P=0.70)$. Adverse events included hypotension, $33 \%$ vs $21.1 \%$ in the intervention and control groups, respectively $(P=0.04)$, post-procedural hypotension, bradycardia, cough and delayed recovery from sedation. The total number of adverse events was 22 in the DEX group and 7 in the propofol group $(\mathrm{P}=0.009)$ (Table 2$)$. The median score of physician satisfaction from sedation during procedure was 4.5 (4-5) and 5 (5-5) and the median score of patient discomfort was 5 (4.5-5) and $5(5-5)$ in the intervention and control groups, respectively $(P=0.01$ and $P=0.1)$.

Table 1

Demographic and baseline clinical characteristics

\begin{tabular}{|c|c|c|c|}
\hline & Dexmedetomidine & Propofol & $P$ value \\
\hline$n$ & 30 & 33 & \\
\hline Age* & $58.76 \pm 15.09$ & $62.96 \pm 9.69$ & 0.19 \\
\hline Male gender & $13(43.3)$ & $23(69.7)$ & 0.03 \\
\hline Weight* & $76.43 \pm 18.99$ & $75.73 \pm 15.44$ & 0.87 \\
\hline ASA score* & $2(2-2)$ & $2(2-3)$ & 0.47 \\
\hline Baseline $\mathrm{CO}^{*} *$ & $35.27 \pm 9.20$ & $37.40 \pm 8.66$ & 0.41 \\
\hline \multicolumn{4}{|l|}{ Procedure type } \\
\hline BAL & 9 & 5 & \multirow[t]{5}{*}{0.55} \\
\hline Bronchoscopy + TBB & 7 & 9 & \\
\hline Bronchoscopy + Cryo TBB & 6 & 5 & \\
\hline EBUS & 5 & 9 & \\
\hline Laser/balloon dilation & 3 & 5 & \\
\hline \multicolumn{4}{|c|}{ *Data presented in mean $\pm S D$ or median + IQR } \\
\hline \multicolumn{4}{|c|}{ ASA-American Society of Anesthesiologists; BAL- bronchoalveolar lavage; } \\
\hline \multicolumn{4}{|c|}{ TBB- transbronchial biopsy; EBUS- endobronchial ultrasound } \\
\hline
\end{tabular}


Table 2

Clinical outcomes for the intervention (dexmedetomidine) and control (propofol) groups

\begin{tabular}{|c|c|c|c|}
\hline & $\begin{array}{l}\text { Dexmedetomidine } \\
\mathrm{N}=30\end{array}$ & $\begin{array}{l}\text { Propofol } \\
\mathrm{N}=33\end{array}$ & $\begin{array}{l}\mathrm{P} \\
\text { value }\end{array}$ \\
\hline Number of desaturation events & $1(0-1)$ & $1(0-2)$ & 0.29 \\
\hline Total desaturation time & $1(0-2)$ & $1(0-3)$ & 0.48 \\
\hline $\begin{array}{l}\text { Number of patients with any desaturation } \\
\text { events }\end{array}$ & 16 & 21 & 0.4 \\
\hline $\mathrm{PcCO} 2$ rise during procedure, $\mathrm{mm} / \mathrm{Hg}$ & $\begin{array}{l}18.45(14.70- \\
22.97)\end{array}$ & $\begin{array}{l}20.65(15.37- \\
30.07)\end{array}$ & 0.46 \\
\hline Time period of $\mathrm{PcCO} 2>50 \mathrm{~mm} / \mathrm{Hg}$ in minutes & $17.5(14.12-27.12)$ & $19.5(7.75-29.75)$ & 0.94 \\
\hline $\begin{array}{l}\text { Maximal level of } \mathrm{PcCO} 2 \text { during procedure } \\
\mathrm{mm} / \mathrm{Hg}\end{array}$ & $\begin{array}{l}56.45(48.85- \\
61.42)\end{array}$ & $\begin{array}{l}55.20(52.82- \\
68.37)\end{array}$ & 0.53 \\
\hline Procedure time & $20(8-35)$ & $21(15-27.5)$ & 0.7 \\
\hline Number of Propofol boluses needed & $2.5(2-5)$ & $2(1.0-2.5$ & 0.016 \\
\hline Total bolus dose & $90(50-109)$ & $58(42-106.5)$ & 0.18 \\
\hline Patient satisfaction \# & $5(4.5-5)$ & $5(5-5)$ & 0.10 \\
\hline Bronchoscopist satisfaction \# & $4.5(4-5)$ & $5(5-5)$ & 0.012 \\
\hline \multicolumn{4}{|l|}{ Adverse events (\%) } \\
\hline Hypotension during procedure & $10(33.3)$ & $4(12.1)$ & 0.04 \\
\hline bradycardia & $2(6.7)$ & 0 & 0.22 \\
\hline Cough & $2(6.7)$ & 0 & 0.22 \\
\hline Post-procedural Hypotension & $5(16.7)$ & $3(9.1)$ & 0.3 \\
\hline Delayed recovery from sedation & $3(10)$ & 0 & 0.10 \\
\hline Total* & 22 & 7 & 0.009 \\
\hline \multicolumn{4}{|c|}{$\begin{array}{l}\text { Data presented as median (IQR); * Five patients had } 2 \text { adverse events; PcCO2: Transcutaneous CO2 } \\
\text { partial pressure }\end{array}$} \\
\hline
\end{tabular}


Overall, 72 trials were assessed for eligibility after the removal of duplicates, 19 articles were evaluated with full text and 13 trials (twelve published trials and the current trial) met the inclusion criteria for this review[16-27] and were included in the final analysis (1604 participants) (Table 3 and Figure S1). The studies were performed between 2012 and 2021 and no ongoing trials were identified. 
Table 3

Included studies in the Systematic review and meta-analysis

\begin{tabular}{|c|c|c|c|c|c|c|}
\hline Study & Design & Procedure & $\begin{array}{l}\text { Intervention } \\
\text { (n) }\end{array}$ & $\begin{array}{l}\text { Comparator } \\
\text { (n) }\end{array}$ & DEX dose & $\begin{array}{l}\text { Primary } \\
\text { outcome }\end{array}$ \\
\hline Ryu $2012^{16}$ & RCT & FB & $\begin{array}{l}\text { PRF- DEX } \\
(36)\end{array}$ & $\begin{array}{l}\text { PRF - rFEN } \\
(36)\end{array}$ & $\begin{array}{l}0.4-2 \\
\mu \mathrm{g} / \mathrm{kg} / \mathrm{H}\end{array}$ & SpO2 \\
\hline Liao $2012^{27}$ & RCT & FB & $\begin{array}{l}\text { DEX } \\
(99)\end{array}$ & $\begin{array}{l}\text { MDZ } \\
(99)\end{array}$ & $\begin{array}{l}0.5 \mu \mathrm{g} / \mathrm{kg} \\
/ \mathrm{H}\end{array}$ & SpO2 \\
\hline $\begin{array}{l}\text { Goneppanavar } \\
2015^{26}\end{array}$ & RCT & FB & $\begin{array}{l}\text { DEX } \\
(27)\end{array}$ & $\begin{array}{l}\text { MDZ } \\
(27)\end{array}$ & $\begin{array}{l}1 \mu \mathrm{g} / \mathrm{kg} \\
\text { once }\end{array}$ & Other ${ }^{a}$ \\
\hline Yuan $2016^{18}$ & RCT & FB & $\begin{array}{l}\text { DEX-FEN } \\
(50)\end{array}$ & $\begin{array}{l}\text { PRF-FEN } \\
(50)\end{array}$ & $\begin{array}{l}0.20 .7 \\
\mu \mathrm{g} / \mathrm{kg} / \mathrm{H}\end{array}$ & $\mathrm{SpO} 2$ \\
\hline Riachy $2017^{25}$ & RCT & FB & LID+DEX (53) & $\begin{array}{l}\text { LID (54) } \\
\text { LID + FEN } \\
(55)\end{array}$ & $\begin{array}{l}0.5 \mu \mathrm{g} / \mathrm{kg} \\
\text { once }\end{array}$ & Other ${ }^{b}$ \\
\hline Li et al $2019^{24}$ & RCT & FB & $\begin{array}{l}\text { DEX+ FEN + } \\
\text { PRF (57) }\end{array}$ & $\begin{array}{l}\text { FEN+ PRF } \\
(57)\end{array}$ & $\begin{array}{l}0.5-1 \\
\mathrm{mg} / \mathrm{kg} \\
\text { once }\end{array}$ & SpO2 \\
\hline St-Pierre $2019^{20}$ & RCT & $\begin{array}{l}\text { EBUS- } \\
\text { TBNA }\end{array}$ & $\begin{array}{l}\text { DEX } \\
(30)\end{array}$ & $\begin{array}{l}\text { rFEN } \\
(30)\end{array}$ & $\begin{array}{l}0.5-1.0 \\
\mu \mathrm{g} / \mathrm{kg} / \mathrm{H}\end{array}$ & SpO2 \\
\hline $\begin{array}{l}\text { Magazine } \\
2020^{23}\end{array}$ & RCT & $\mathrm{FB}$ & $\begin{array}{l}\text { DEX } \\
(27)\end{array}$ & $\begin{array}{l}\text { MDZ } \\
(27)\end{array}$ & $\begin{array}{l}0.5 \mu \mathrm{g} / \mathrm{kg} \\
\text { once }\end{array}$ & Other ${ }^{a}$ \\
\hline $\operatorname{Lin} 2020^{19}$ & RCT & $\begin{array}{l}\text { EBUS- } \\
\text { TBNA }\end{array}$ & $\begin{array}{l}\text { DEX } \\
(25)\end{array}$ & $\begin{array}{l}\text { PRF } \\
(25)\end{array}$ & $\begin{array}{l}0.5-1.4 \\
\mu \mathrm{g} / \mathrm{kg} / \mathrm{H}\end{array}$ & SpO2 \\
\hline $\operatorname{Kim} 2021^{22}$ & RCT & $\begin{array}{l}\text { EBUS- } \\
\text { TBNA }\end{array}$ & $\begin{array}{l}\text { DEX } \\
(48)\end{array}$ & $\begin{array}{l}\text { MDZ } \\
(54)\end{array}$ & $\begin{array}{l}0.25-0.75 \\
\mu \mathrm{g} / \mathrm{kg} / \mathrm{H}\end{array}$ & SpO2 \\
\hline Kumari $2021^{21}$ & RCT & $\begin{array}{l}\text { EBUS- } \\
\text { TBNA }\end{array}$ & $\begin{array}{l}\text { DEX } \\
(99)\end{array}$ & $\begin{array}{l}\text { MDZ } \\
\text { (98) }\end{array}$ & $\begin{array}{l}0.6 \mu \mathrm{g} / \mathrm{kg} \\
/ \mathrm{H}\end{array}$ & Other ${ }^{c}$ \\
\hline Zhang $2021^{17}$ & RCT & $\mathrm{FB}$ & $\begin{array}{l}\text { DEX } \\
(222)\end{array}$ & $\begin{array}{l}\text { FEN } \\
(211)\end{array}$ & $\begin{array}{l}1 \mu \mathrm{g} / \mathrm{kg} \\
\text { once }\end{array}$ & SpO2 \\
\hline $\begin{array}{l}\text { Pertzov } 2021 \\
\text { (current study) }\end{array}$ & RCT & FB & $\begin{array}{l}\text { DEX } \\
(30)\end{array}$ & $\begin{array}{l}\text { PRF } \\
\text { (33) }\end{array}$ & $\begin{array}{l}0.5 \mu \mathrm{g} / \mathrm{kg} \\
/ \mathrm{H}\end{array}$ & SpO2 \\
\hline
\end{tabular}


(n) (n)

FB - flexible bronchoscopy; CS - Conscious sedation; GA - general anesthesia; MDS - Moderate to deep sedation; DEX - dexmedetomidine; PRF - propofol; MDZ - midazolam; FEN - fentanyl; rFEN remifentanil; LID - lidocaine;

EBUS-TBNA- endobronchial ultrasound -guided transbronchial needle aspiration

a - Composite outcome: sedation, cough, calmness, respiratory response, physical movement, facial tension

b - procedure tolerance, sedation level, safety

c - number of rescue midazolam boluses

\section{Risk of bias in included studies}

The risk of bias assessment varied between trials, three trials had a low risk of bias with adequate allocation concealment, randomization, blinding and sample size[21, 22, 25]. Three trials had an adequate allocation concealment, randomization, and blinding although, with a small sample size that may cause a bias in reported results[16, 23, 26]. Four trials were randomized with adequate allocation concealment randomization and sample size but were not blinded[17, 18, 24, 27]. And three randomized trials, including the current trial, were not blinded and with a small sample size[19, 20]. All studies reported results by ITT. The detailed methodological quality of individual trials is shown in Figure S2 and S3.

\section{Primary outcome}

\section{Number of desaturation events}

Twelve trials (1490 participants) reported the number of patients with any desaturation event. Patients treated with DEX for sedation during bronchoscopy showed a lower rate of desaturation events in comparison to the control group (RR $0.67,95 \% \mathrm{Cl} 0.57$ to 0.79 ) (Figure 1 ). The certainty of evidence was high since all studies were RCTs, the number of participants was high, and the results were consistent across trials.

\section{Secondary outcomes}

Predefined secondary outcomes were hypotension, hypertension, bradycardia, and tachycardia. However, most studies did not report the rates of hypertension and tachycardia therefore, the analysis included only hypotension and bradycardia.

\section{Hypotension during bronchoscopy}


Data for hypotension events during the procedure was reported in 12 trials. The analysis included 1544 participants and showed a significantly higher rate of hypotension events in the DEX arm (RR 1.55, 95\% $\mathrm{Cl} 1.16$ to $2.06 ; \mathrm{I}^{2}=34 \%$ ) (Figure 2 ). The certainty of evidence for this analysis was moderate due to inconsistency and imprecision.

\section{Bradycardia during bronchoscopy}

Data for Bradycardia events during the procedure was reported in 12 trials. The analysis including 1490 participants and showed a higher rate of bradycardia events in the DEX group (RR 1.91, 95\% $\mathrm{Cl} 1.04$ to 3.51) (Figure 3). Significant heterogeneity was evident $\left(I^{2}=53 \%\right)$. The certainty of evidence for this analysis was moderate due to a wide confidence interval and inconsistency.

\section{Discussion}

In this study we have evaluated the efficacy and safety of DEX in comparison to propofol for sedation during bronchoscopy procedures. The results showed no difference in oxygen saturation, both in the number of desaturation events and in the total desaturation time (in which the oxygen saturation was lower than $90 \%$. The level of $\mathrm{CO} 2$ was also similar between treatment groups, there was no difference in the median rise in PcCO2 during procedure and in the total time period in which the PcCO2 level was above $50 \mathrm{~mm} / \mathrm{Hg}$. The DEX group however, showed inferior performance in the adequacy of sedation, patients in the intervention group required a significantly higher number of propofol rescue boluses during the procedure, due to unsatisfactory level of sedation. Moreover, use of DEX was associated with a significantly higher frequency of adverse events including hypotension. Finally, the level of physician satisfaction was significantly lower in the DEX group. The results of this study join a large number of small RCTs that were conducted in recent years, with diverse results regarding respiratory and hemodynamic outcomes[16-27]. For a more accurate and concise view of recent published results and to mitigate the current study's limitations (i.e., small sample size and lack of blinding), we conducted a systematic review and meta-analysis of all RCTs that evaluated the efficacy of DEX during bronchoscopy and included the results of the current trial.

While individual RCT results were diverse, the pooled analysis gave a conclusive result that showed a significantly lower rate of desaturation events in patients treated with DEX sedation ( $R R=0.67,95 \% \mathrm{Cl} 0.57$ to 0.79 ) in comparison to patients treated with propofol, fentanyl or midazolam. The quality of evidence was high with low heterogeneity. To our knowledge this is the first systematic review and meta-analysis conducted to evaluate efficacy of DEX sedation during bronchoscopy and these results encourage the use of this drug in selected patients. Patients with desaturation or chronic lung disease will benefit from DEX sedation. However, the drug should be avoided in patients with a high risk of arrythmias or patients with heart failure, due to a higher rate of hypotension and bradycardia adverse events seen in the DEX group. Future trials should evaluate single dose versus continuous DEX sedation, different doses and different comparator drugs and combinations. 
Additional outcomes evaluated in the current study, were the level of sedation obtained and bronchoscopist satisfaction. For both we found DEX was inferior to propofol. However, our results are not in agreement with similar trials that reported no difference in the level of sedation except one trial that reported superior sedation with DEX in comparison to midazolam [19-22]. Since these outcomes are quite subjective, differences between trials are expected, these differences may be reduced by using validated scores and agreed drugs and dosage for rescue boluses.

In conclusion, dexmedetomidine is suitable for sedation during bronchoscopy. Moreover, a pooled analysis of RCTs showed a significantly reduced rate of desaturation events with DEX sedation in comparison to propofol, midazolam and fentanyl. However, DEX sedation was associated with a higher rate of hypotension and bradycardia adverse events.

\section{List Of Abbreviations}

DEX: dexmedetomidine

RCT: Randomized controlled trials

IQR: Inter quartile range

Cl: Confidence interval

FOB: Fiberoptic bronchoscopy

ERCP: Endoscopic retrograde cholangio-pancreatography

RMC: Rabin medical center

IRB: institutional review board

PcCO2: transcutaneous carbon dioxide partial pressure

RR: relative risk

ITT: intention to treat

\section{Declarations}

\section{Ethics approval and consent to participate}

Subjects have given their written informed consent. The study protocol has been approved by the institutes' Ethical Review Board (RMC-0312-19). The study protocol was registered in a clinical trial registry (NCT04211298, registration date:26/12/2019). https://clinicaltrials.gov/ct2/show/NCT04211298 
Not Applicable

\section{Availability of data and materials}

The datasets used and/or analyzed during the current study available from the corresponding author on reasonable request

\section{Competing interests}

The authors have no conflict of ethics to declare

\section{Funding}

None

\section{Authors' contributions}

BP, BK, SI and KA collected the data, KM and DR and SY performed the procedures, SI and BP performed the statistical analysis and wrote the manuscript. KM, DR and YS revised the manuscript.

\section{Acknowledgements}

The authors express their gratitude to Ms. Dalia Dawn Orkin for her English language editing services.

\section{References}

1. Du Rand IA, Blaikley J, Booton R, Chaudhuri N, Gupta V, Khalid S, et al. Summary of the British Thoracic Society guideline for diagnostic flexible bronchoscopy in adults. Thorax. 2013 Aug;68(8):786-7.

2. Guidelines for fiberoptic bronchoscopy in adults. American Thoracic Society. Medical Section of the American Lung Association. Am Rev Respir Dis. 1987 Oct;136(4):1066.

3. Sarkiss M. Anesthesia for bronchoscopy and interventional pulmonology: from moderate sedation to jet ventilation. Curr Opin Pulm Med. 2011 Jul;17(4):274-8.

4. Goudra BG, Singh PM, Borle A, Farid N, Harris K. Anesthesia for Advanced Bronchoscopic Procedures: State-of-the-Art Review. Lung. 2015 Aug;193(4):453-65.

5. Barends CRM, Absalom A, van Minnen B, Vissink A, Visser A. Dexmedetomidine versus Midazolam in Procedural Sedation. A Systematic Review of Efficacy and Safety. PloS One. 2017;12(1):e0169525.

6. Naaz S, Ozair E. Dexmedetomidine in current anaesthesia practice- a review. J Clin Diagn Res JCDR. 2014 Oct;8(10):GE01-04.

7. Goyal R, Hasnain S, Mittal S, Shreevastava S. A randomized, controlled trial to compare the efficacy and safety profile of a dexmedetomidine-ketamine combination with a propofol-fentanyl combination for ERCP. Gastrointest Endosc. 2016 May;83(5):928-33. 
8. Eberl S, Preckel B, Bergman JJ, van Dieren S, Hollmann MW. Satisfaction and safety using dexmedetomidine or propofol sedation during endoscopic oesophageal procedures: A randomised controlled trial. Eur J Anaesthesiol. 2016;33(9):631-7.

9. Zhang X-K, Chen Q-H, Wang W-X, Hu Q. Evaluation of dexmedetomidine in combination with sufentanil or butorphanol for postoperative analgesia in patients undergoing laparoscopic resection of gastrointestinal tumors: A quasi-experimental trial. Medicine (Baltimore). 2016 Dec;95(50):e5604.

10. Lu Z, Li W, Chen H, Qian Y. Efficacy of a Dexmedetomidine-Remifentanil Combination Compared with a Midazolam-Remifentanil Combination for Conscious Sedation During Therapeutic Endoscopic Retrograde Cholangio-Pancreatography: A Prospective, Randomized, Single-Blinded Preliminary Trial. Dig Dis Sci. 2018 Jun;63(6):1633-40.

11. Kinugasa H, Higashi R, Miyahara K, Moritou Y, Hirao K, Ogawa T, et al. Dexmedetomidine for conscious sedation with colorectal endoscopic submucosal dissection: a prospective double-blind randomized controlled study. Clin TransI Gastroenterol. 2018 04;9(7):167.

12. Ghali A, Mahfouz AK, Ihanamäki T, El Btarny AM. Dexmedetomidine versus propofol for sedation in patients undergoing vitreoretinal surgery under sub-Tenon's anesthesia. Saudi J Anaesth. 2011 Jan;5(1):36-41.

13. Jalowiecki P, Rudner R, Gonciarz M, Kawecki P, Petelenz M, Dziurdzik P. Sole use of dexmedetomidine has limited utility for conscious sedation during outpatient colonoscopy. Anesthesiology. 2005 Aug;103(2):269-73.

14. Cooper L, Candiotti K, Gallagher C, Grenier E, Arheart KL, Barron ME. A randomized, controlled trial on dexmedetomidine for providing adequate sedation and hemodynamic control for awake, diagnostic transesophageal echocardiography. J Cardiothorac Vasc Anesth. 2011 Apr;25(2):233-7.

15. Kaygusuz K, Gokce G, Gursoy S, Ayan S, Mimaroglu C, Gultekin Y. A comparison of sedation with dexmedetomidine or propofol during shockwave lithotripsy: a randomized controlled trial. Anesth Analg. 2008 Jan;106(1):114-9, table of contents.

16. Ryu JH, Lee SW, Lee JH, Lee EH, Do SH, Kim CS. Randomized double-blind study of remifentanil and dexmedetomidine for flexible bronchoscopy. Br J Anaesth. 2012 Mar;108(3):503-11.

17. Zhang Q, Zhou J, He Q, Guan S, Qiu H, Xu X, et al. Dexmedetomidine combined with midazolam infusion guided by bispectral index during bronchoscopy. Clin Respir J. 2021 May DOI: $10.1111 /$ crj. 13383

18. Yuan F, Fu H, Yang P, Sun K, Wu S, Lv M, et al. Dexmedetomidine-fentanyl versus propofol-fentanyl in flexible bronchoscopy: A randomized study. Exp Ther Med. 2016 Jul;12(1):506-12.

19. Lin T-Y, Huang Y-C, Kuo C-H, Chung F-T, Lin Y-T, Wang T-Y, et al. Dexmedetomidine sedation for endobronchial ultrasound-guided transbronchial needle aspiration, a randomised controlled trial. ERJ Open Res. 2020 Oct;6(4). DOI: 10.1183/23120541.00064-2020

20. St-Pierre P, Tanoubi I, Verdonck O, Fortier L-P, Richebé P, Côté I, et al. Dexmedetomidine Versus Remifentanil for Monitored Anesthesia Care During Endobronchial Ultrasound-Guided Transbronchial Needle Aspiration: A Randomized Controlled Trial. Anesth Analg. 2019 Jan;128(1):98-106. 
21. Kumari R, Jain K, Agarwal R, Dhooria S, Sehgal IS, Aggarwal AN. Fixed dexmedetomidine infusion versus fixed-dose midazolam bolus as primary sedative for maintaining intra-procedural sedation during endobronchial ultrasound-guided transbronchial needle aspiration: a double blind randomized controlled trial. Expert Rev Respir Med. 2021 Apr;1-7.

22. Kim J, Choi SM, Park YS, Lee C-H, Lee S-M, Yoo C-G, et al. Dexmedetomidine versus midazolam for sedation during endobronchial ultrasound-guided transbronchial needle aspiration: A randomised controlled trial. Eur J Anaesthesiol. 2021 May;38(5):534-40.

23. Magazine R, Venkatachala SK, Goneppanavar U, Surendra VU, Guddattu V, Chogtu B. Comparison of midazolam and low-dose dexmedetomidine in flexible bronchoscopy: A prospective, randomized, double-blinded study. Indian J Pharmacol. 2020 Feb;52(1):23-30.

24. Li H, Zhang N, Zhang $K$, Wei Y. Observation of the clinical efficacy of dexmedetomidine in flexible bronchoscopy under general anesthesia: clinical case experience exchange. J Int Med Res. 2019 Dec;47(12):6215-22.

25. Riachy M, Khayat G, Ibrahim I, Aoun Z, Dabar G, Bazarbachi T, et al. A randomized double-blind controlled trial comparing three sedation regimens during flexible bronchoscopy: Dexmedetomidine, alfentanil and lidocaine. Clin Respir J. 2018 Apr;12(4):1407-15.

26. Goneppanavar U, Magazine R, Periyadka Janardhana B, Krishna Achar S. Intravenous Dexmedetomidine Provides Superior Patient Comfort and Tolerance Compared to Intravenous Midazolam in Patients Undergoing Flexible Bronchoscopy. Pulm Med. 2015;2015:727530.

27. Liao W, Ma G, Su QG, Fang Y, Gu BC, Zou XM. Dexmedetomidine versus midazolam for conscious sedation in postoperative patients undergoing flexible bronchoscopy: a randomized study. $\mathrm{J}$ Int Med Res. 2012;40(4):1371-80.

28. James Thomas JH. Cochrane Handbook for Systematic Reviews of Interventions [Internet]. 2019 [cited 2020 Apr 21]. Available from: /handbook/current

29. Moher D, Liberati A, Tetzlaff J, Altman DG, Group TP. Preferred Reporting Items for Systematic Reviews and Meta-Analyses: The PRISMA Statement. PLOS Med. 2009 Jul;6(7):e1000097.

30. Higgins JPT, Thompson SG, Deeks JJ, Altman DG. Measuring inconsistency in meta-analyses. BMJ. 2003 Sep;327(7414):557-60.

31. Guyatt GH, Oxman AD, Vist GE, Kunz R, Falck-Ytter Y, Alonso-Coello P, et al. GRADE: an emerging consensus on rating quality of evidence and strength of recommendations. BMJ. 2008 Apr;336(7650):924-6.

32. Mustafa RA, Santesso N, Brozek J, AkI EA, Walter SD, Norman G, et al. The GRADE approach is reproducible in assessing the quality of evidence of quantitative evidence syntheses. J Clin Epidemiol. 2013 Jul;66(7):736-42; quiz 742.e1-5.

\section{Figures}




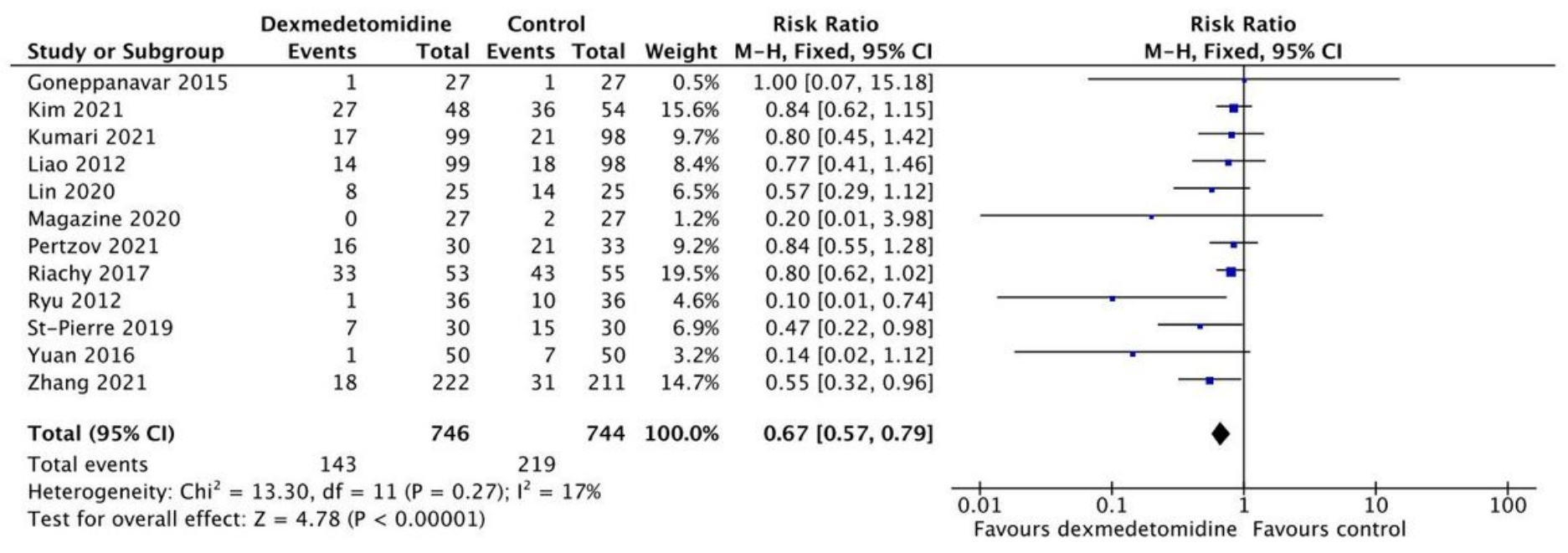

\section{Figure 1}

Systematic review and meta-analysis primary outcomes: Forest plot presenting the rate of desaturation events.

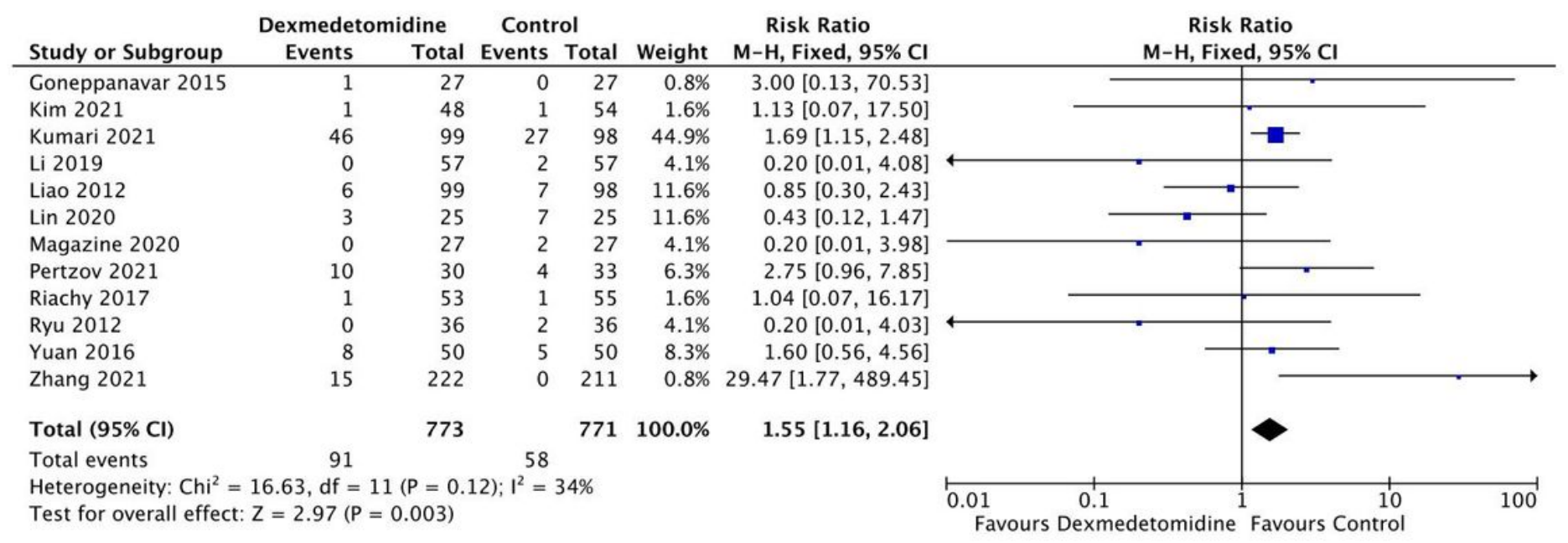

Figure 2

Systematic review and meta-analysis secondary outcomes: Forest plot presenting the rate of hypotension events during bronchoscopy. 


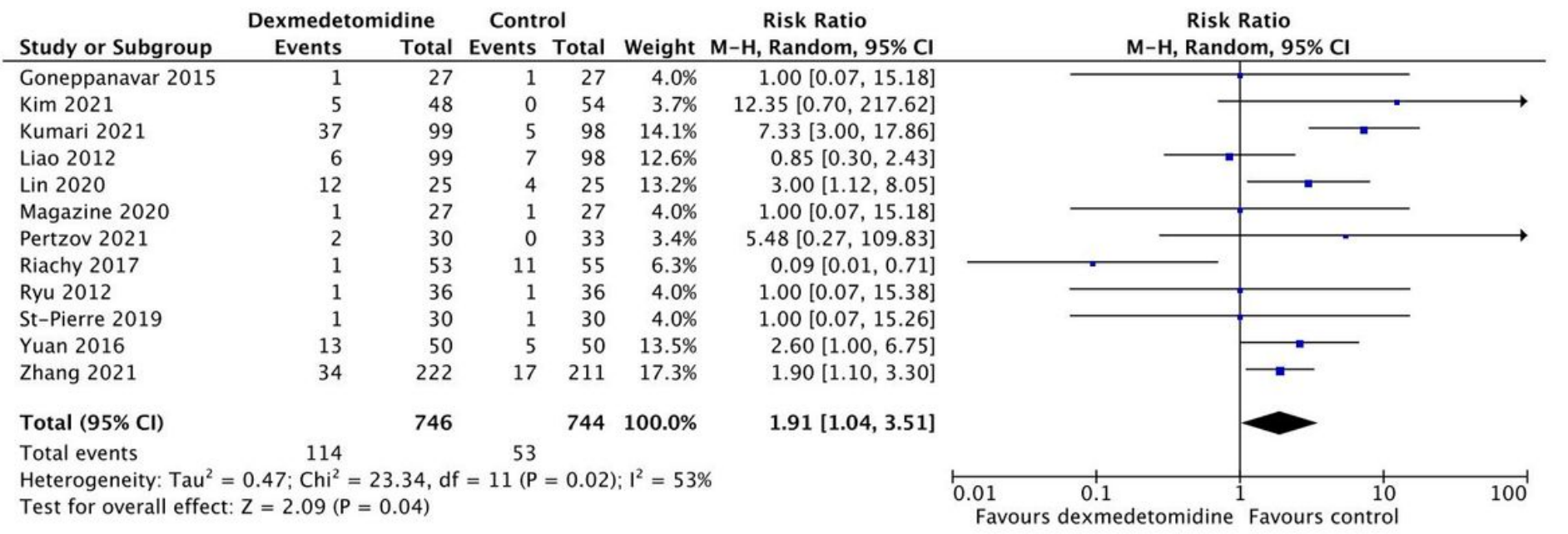

\section{Figure 3}

Systematic review and meta-analysis secondary outcomes: Forest plot presenting the rate of bradycardia events during bronchoscopy.

\section{Supplementary Files}

This is a list of supplementary files associated with this preprint. Click to download.

- supplementryDEX092021.docx 